\title{
Comparative Analysis of Two Compact and Highly Efficient Resonant Switched Capacitor Converters
}

\author{
Miroslav Vasić ${ }^{1}$, Diego Serrano ${ }^{1}$, Pedro Alou ${ }^{1}$, Jesús A. Oliver ${ }^{1}$, Petar Grbović ${ }^{\text {, José A. Cobos }}{ }^{1}$ \\ ${ }^{1}$ Universidad Politécnica de Madrid, Centro de Electrónica Industrial, Madrid, Spain \\ ${ }^{2}$ Huawei European Research Center, Munich, Germany
}

\begin{abstract}
In this paper we compare two resonant switched capacitor converters in which the resonant inductor can be placed in series with a resonant capacitor (AC side), conducting a sinusoidal current, or it can be placed in series with the input source (DC side), conducting rectified sinusoidal current. Both resonant converters have the same voltage gain, and although the change in the position of the resonant inductor is, at first glance, of minor importance, the analysis and results show that it has huge impact on the capability to achieve ZVS transitions at low output power and on the inductor design and power losses. The experimental results show that for circuit with the resonant inductor in the AC side, the ZVS transitions produce an effective switching frequency significantly higher than the resonant frequency which forces the implementation of cycle skipping at light loads. The difference between the power losses in these two approaches is between $3 \mathrm{~W}$ and $5 \mathrm{~W}$. The prototype implemented for the experiments provides up to $4.5 \mathrm{~kW}$ with $33.3 \mathrm{~W}$ power loss $(99.3 \%$ efficiency). In the case of light load $(1.5 \mathrm{~kW})$ power losses are only $8.25 \mathrm{~W}(\eta=\mathbf{9 9 . 4 5 \%})$. Its power density is higher than $65 \mathrm{~kW} / \mathrm{dm}^{3}$.
\end{abstract}

Keywords-Resonant converters, switched capacitors, zero voltage switching

\section{INTRODUCTION}

Power conversion systems can generally be grouped into single-stage architectures and multi-stage architectures. Although the multi-stage architectures are usually costly and more complex they are used in the cases when the single-stage approach cannot achieve high performance while meeting requirements such as wide operating range, high power density and efficiency. In a multi-stage approach each part of the system is optimally designed to address one part of the desired requirements. Recently, this approach has been applied to achieve highly compact and dense solutions, decreasing the size of the passive components [1-3]. What is common in the recently presented works, it is that the first stage is based on a switched capacitor converter which provides multiple voltage levels in an efficient way. Using multilevel converters the size and power losses of magnetic components, inductors and transformers, the most bulky components, in dc-dc converters, are decreased.

Switched capacitor converters (SCC) have been used as a simple and low cost dc-dc converter in low power applications, [4-6]. These converters normally operate with fixed voltage gains, but with extremely high efficiency. Additionally, due to the lack of magnetic components, they occupy very small volume obtaining ultra-high power densities. Nevertheless, one of the important issues of these converters are the switching losses, especially if the load power reaches $\mathrm{kW}$ levels. In order to avoid high switching losses, a resonant inductor is combined with the "flying" capacitor, producing a resonance and, by correct timing of the transistor control signals, it is possible to obtain soft-switching transitions, Zero Voltage Switching (ZVS). As a consequence, the Resonant Switched Capacitor Converter (RSCC) extends the power range of SCC to highpower applications [7-10]. The resonant inductor is smaller than the inductor employed in classical PWM converters because it does not have to store the energy, just produce the resonance. A voltage divider based on a switching capacitor is a very well-known solution [11-12] and in this paper two resonant switching capacitor converters based on the voltage divider are compared. Figures 1 and 2 show simplified schematics of solutions in which the resonant inductor can be placed in series with the resonant capacitor conducting a sinusoidal current or it can be placed in the DC path of the current, conducting the rectified sinusoidal current. Both resonant converters have the same voltage gain, and although the change in the position of the resonant inductor is, at first glance, of minor importance, the analysis and results show that it has huge impact on the capability to achieve ZVS transitions at low output power and on the inductor design and power losses. The analyzed converters were designed for input voltage between $300 \mathrm{~V}$ and $500 \mathrm{~V}$, providing up to $4.5 \mathrm{~kW}$ of output power. This fixed gain power converter can be used in applications such as PV boost converter where a high voltage gain and high efficiency in combination with low specific weight is needed.

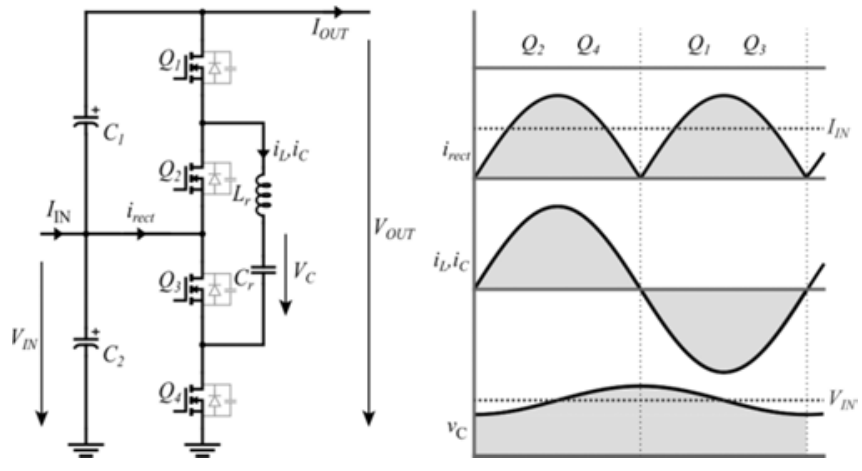

Fig. 1. Resonant Switched Capacitor Converter - with AC resonant inductor 

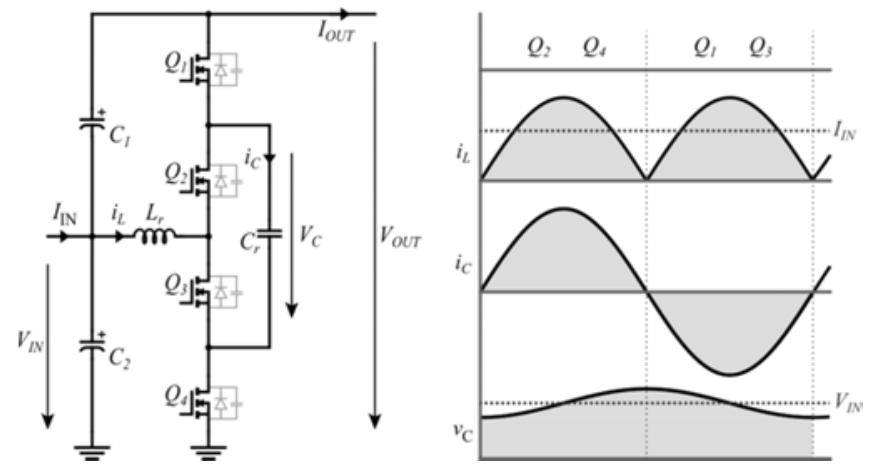

Fig. 2. Resonant Switched Capacitor Converter - with DC resonant inductor

Hybrid converters using this resonant switched capacitor converter in high power application are previously presented and explained in [13-14], while the analyzed RSCC is presented in [15] as a part of a hybrid boost rectifier.

\section{Operating PRINCIPLE OF THE RESONANT SWITCHED CAPACITOR CONVERTER}

Simplified schematic of the resonant switched capacitor converter with the most important waveforms is shown in Figures 1 and 2. In the case when the resonant inductor is placed in series with the resonant capacitor, its current is purely sinusoidal due to the resonance and due to the fact that the average value of the capacitor current has to be zero. This case we will denominate as a converter with $\mathrm{AC}$ resonant inductor. The duty cycle of the converter is, approximately, $50 \%$. During the first half of the switching cycle the resonant network is connected to capacitor $\mathrm{C}_{2}$ and the load current completely flows through $\mathrm{C}_{1}$. During this period of time the resonant capacitor is charged from the input source. In the second half of the switching cycle, the resonant network is connected in parallel to $C_{1}$ and its role is to compensate the charge taken from $C_{1}$ in the first half of the switching period and to provide the load current. Therefore, we can write the following equations for the $\mathrm{C}_{1}$ current:

$$
\begin{gathered}
i_{C 1}=I_{o} \quad t \in\left[0, \frac{T}{2}\right] \\
i_{C 1}=I_{o}-I_{R} \sin (\omega t) \quad t \in\left[\frac{T}{2}, T\right]
\end{gathered}
$$

where $I_{0}$ is the load current, and $I_{R}$ the amplitude of the resonant current. As the net charge of this capacitor must be equal to zero over one switching period by averaging its current it is obtained that:

$$
I_{R}=\pi I_{o}
$$

If we analyze the current $\mathrm{I}_{\text {rect }}$ that flows between the middle point of $\mathrm{C}_{1}$ and $\mathrm{C}_{2}$ and the middle point of $\mathrm{Q}_{2}$ and $\mathrm{Q}_{3}$ we can conclude that this current has the waveform of the rectified resonant current. Therefore, if we place the resonant inductor between these points, the resonance will be maintained and the circuit will provide output voltage two times higher than the input just like in the previous case. This case we will denominate as a converter with DC resonant inductor. Although there is no difference how these two circuits operate, the inductor displacement produces two important changes.
The first one is obvious and it is related with the current through the resonant inductor. The rectified sine wave current has major part of its spectrum in the DC part, therefore, it is possible to exploit low DC resistance of the windings and decrease the power losses in the windings. Nevertheless, the core losses are influenced by the frequency and amplitude of the magnetic flux change. The excursion of the magnetic flux is just one half in comparison with the original design, but double the resonant frequency. This might provoke higher core losses in the design. The second important change is regarding the control signals sent to the switches in order to obtain the ZVS transitions, like it is shown in Figures 3 and 4. During this transition two transistors must be turned off and two transistors turned on. In case of both analyzed converters the ZVS transition starts when one conducting transistor is turned off. It has to be turned off with sufficiently high current level, $\mathrm{I}_{\text {open }}$, in order to have enough energy in the resonant inductor to accomplish soft transition. The first ZVS transition occurs between $t_{1}$ and $t_{4}$ in Figures 3 and 4 . During this time the resonant current interacts with transistor's $\mathrm{C}_{\text {oss }}$ capacitances. In this paper the analyzed converter can operate up to $1000 \mathrm{~V}$ and for this reason the employed devices are $\mathrm{Si}$ CoolMOS transistors that exhibit highly nonlinear $\mathrm{C}_{\text {oss }}$. This capacitance could be modelled with a piecewise linear characteristic and roughly approximated with only two values. Due to this nonlinearity, the resonant current does not have a linear shape between $t_{1}$ and $t_{2}$. Figure 5 shows more details regarding this transition.

Ideally, the resonant current and voltage across $\mathrm{C}_{\text {oss }}$ reach zero at $t_{2}$. Nevertheless, in order to have both conditions fulfilled, the energy in the resonant inductor at $t_{1}$ has to be considerably high, especially if there are several transistors in parallel per switch. This can be obtained or by increasing the level of the resonant current in the moment when the ZVS transition is started or by increasing the value of the inductor. The first approach leads to higher turn off losses, while the second one to an unacceptably bulky inductor. Therefore, a trade-off mast be made by performing a "partial ZVS", i.e. the switch is closed when the voltage across $\mathrm{C}_{\text {oss }}$ reaches $20 \mathrm{~V}-40 \mathrm{~V}$, [16]. In another words, at $t_{2}$ only the resonant current will reach zero.

During very short period of time, from $t_{2}$ to $t_{3}$ there will be two transistors conducting in both converters and actually this time period can be skipped, although inherently will exist due to driver delays during very short moment. The second ZVS transition occurs from $t_{3}$ to $t_{4}$. During this time period the resonant current is becoming more negative and the energy of the resonant inductor is rising. Therefore, during this time period it is possible to obtain full ZVS, fully discharging $\mathrm{C}_{\text {oss }}$ of the turned off transistor. Until $t_{4}$ the resonant current behaves in the same way in both analyzed converters and in both cases it will approximately reach value of

$$
I_{n e g}=-\sqrt{\frac{2 V_{i n} V_{0} C_{0} N}{L}}
$$



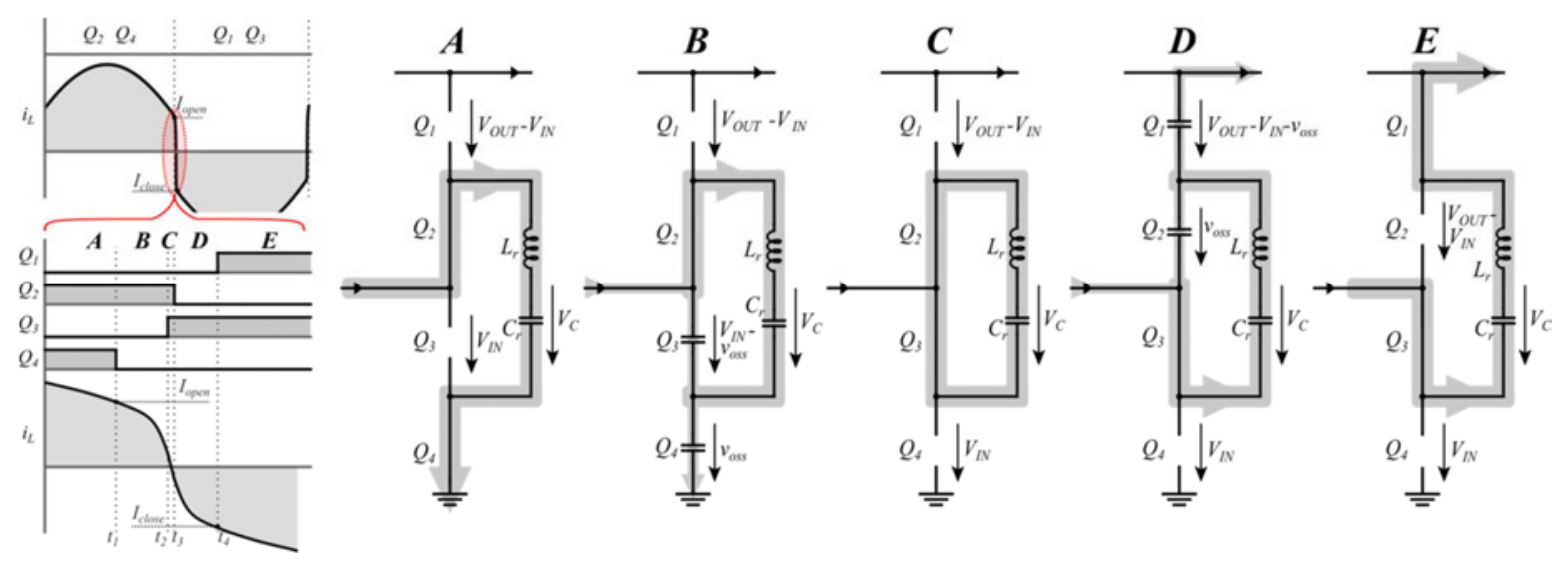

Fig 3 ZVS transition in the case of the Resonant Switched Capacitor Converter with an AC resonant inductor
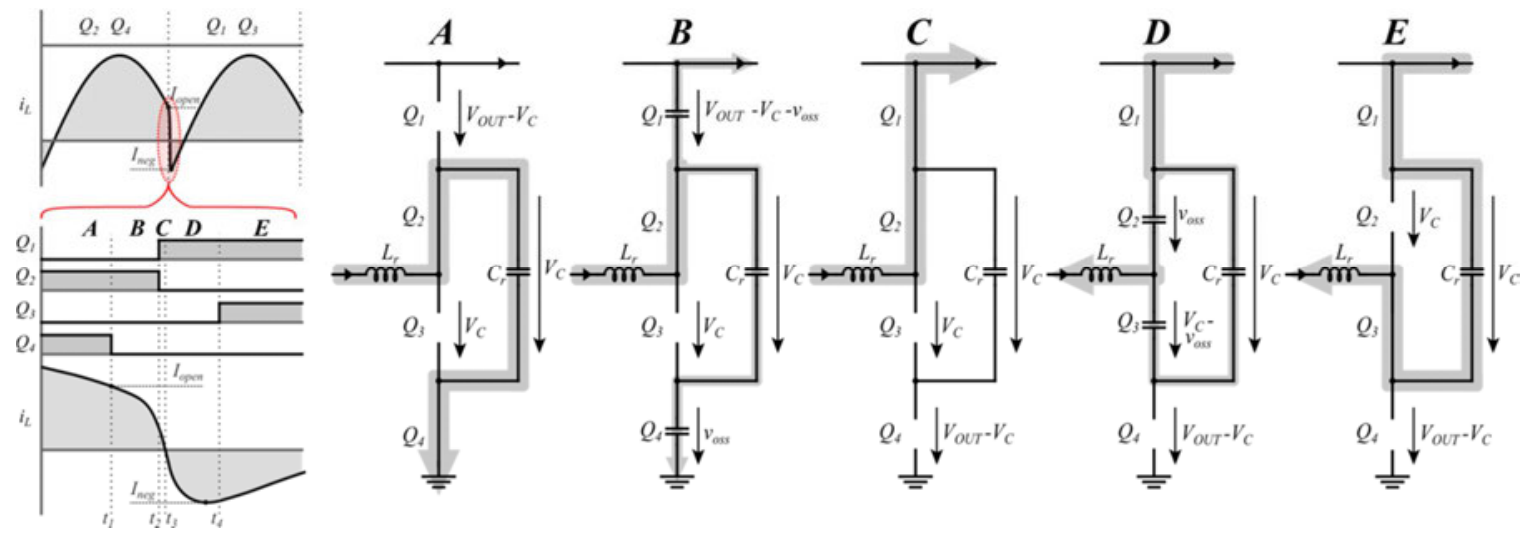

Fig 4 ZVS transition in the case of the Resonant Switched Capacitor Converter with a DC resonant inductor

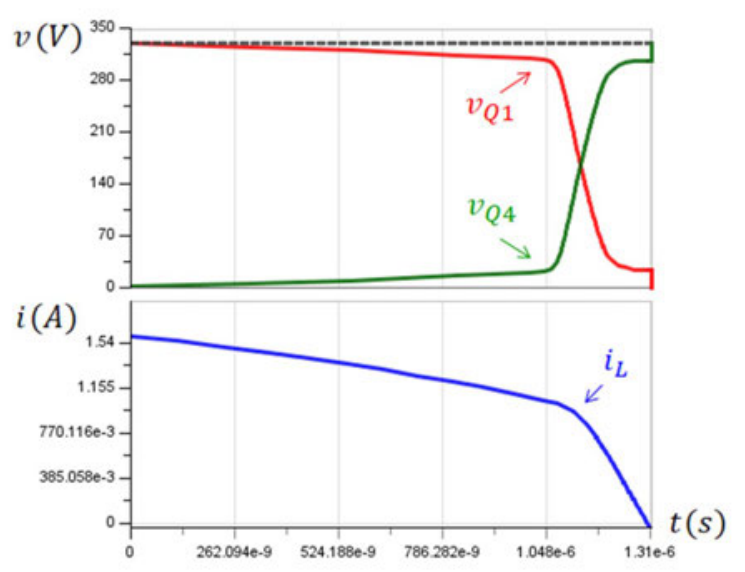

After $t_{4}$, the resonant current is negative and in the case of the converter with $\mathrm{AC}$ resonant inductor it will decrease, while in the case of the converter with DC resonant inductor it will start increasing. This is the key difference between the analyzed converters as it has a major impact on the switching frequency. The difference in the switching frequency comes from a fact that in the case of the DC resonant inductor the resonant current has to change its sign, reach value of $\mathrm{I}_{\mathrm{R} 1} \approx \pi \mathrm{I}_{0}$ and then fall to $\mathrm{I}_{\text {open. }}$. This lasts very close to a half of the resonant period. On the other hand, with the $\mathrm{AC}$ resonant inductor, the resonant current decreases to $-\mathrm{I}_{\mathrm{R} 2} \approx-\pi \mathrm{I}_{0}$ and then rises to $-\mathrm{I}_{\mathrm{open}}$, as shown in Figure 3. In this case the switching period is obviously shorter than the resonance and it will depend on the value of the load current, i.e. the difference between the $-I_{R}$ and $I_{\text {min }}$. This difference is shorter as the load current is decreased and in some extreme cases when $I_{\min }$ decreases to $-I_{R}$ the switching frequency can be almost double

Fig. 5. Partial ZVS transition from $\mathrm{t}_{1}$ to $\mathrm{t}_{2}$

where $\mathrm{N}$ is the number of the transistors in parallel, $\mathrm{L}$ the value of the resonant inductor and the $\mathrm{C}_{\text {oss }}$ is modelled as:

$$
C_{\text {oss }}=\left\{\begin{array}{cc}
C_{0}, & V_{d s}<V_{0} \\
0 & V_{d s}>V_{0}
\end{array}\right.
$$
case of the converter with $\mathrm{AC}$ resonant inductor the switching frequency will be load dependent and that the lower the load the higher the switching frequency which leads to high switching losses at light load which is exactly what should be avoided. 


\section{DESIGN, ANALYSIS AND COMPARISON OF RESONANT CONVERTERS}

Both converters were designed by exploring the very limits from the point of view of the converter's efficiency and size. The design has been performed by modelling inductor and semiconductor losses and obtaining the Pareto front of the both designs. The electrical specifications are presented in Table 1 and obtained Pareto front in Figure 6. The Pareto front is obtained for the nominal conditions, but each design can survive the worst case. As it can be seen, there are significantly less solutions for the converter design with the $\mathrm{AC}$ resonant inductor. The minimum power losses in this case are around $6.5 \mathrm{~W}$ and the minimum volume around $50 \mathrm{~cm}^{3}$. The fact that the resonant current is a sine wave influences the conduction losses so much that the power losses in the case of the DC resonant inductor can be up to $2 \mathrm{~W}$ less. Additionally, for low volume designs it is necessary to use a small inductance and in the case of the $\mathrm{AC}$ resonant inductor where the switching frequency is load dependent this leads to undesirably high switching losses and limits the minimum volume. The theoretical analysis has shown that by changing the position of the resonant inductor it is possible to decrease the volume of the RSCC by $30 \%$ while the power losses could be, almost, halved for the same converter volume. However, the most important conclusion is that using the DC resonant converter it is possible to find solutions that are more efficient and smaller than any other RSCC implemented with an AC resonant inductor.

For the prototype design designs that have power losses up to $6 \mathrm{~W}$ and volumes less than $55 \mathrm{~cm}^{3}$ were selected as possible candidates. After more detailed thermal analysis of the resonant inductor the design from Table 2 was selected. As it can be seen the final resonant inductor was implemented with MPP magnetic material as it showed better results than the ferrite inductor of identical volume from the point of view of core losses. The resonant inductor implemented with MPP material will have decreased inductance at high current levels, which will produce a resonant response that will not be purely sinusoidal, but this does not cause any problem as it will be shown later in experiments. For the bus capacitors, $\mathrm{C}_{1}$ and $\mathrm{C}_{2}$, Ceralink capacitors were selected due to their high power density. On the other hand, the resonant capacitor was implemented with a Multilayer Ceramic Capacitor (MCC). Different dielectrics such as $\mathrm{C} 0 \mathrm{G}, \mathrm{X} 6 \mathrm{~S}$ or $\mathrm{X} 7 \mathrm{~T}$ could be selected. Nevertheless, after a series of experiments in which the resonant capacitor was stressed and the temperature rise was observed [17] X7T was chosen. It is interesting to notice that film based capacitors would provide better converter robustness as their temperature rise is significantly lower, but they occupy some more space than X7T MCC, Figure 7.

TABLE I: ELECTRICAL SPECIFICATIONS OF THE ANALYZED RESONANT CONVERTER

\begin{tabular}{|l|c|}
\hline Input voltage range & $350 \mathrm{~V}-500 \mathrm{~V}$ \\
\hline Maximum output power & $4.5 \mathrm{~kW}$ \\
\hline Nominal input voltage & $580 \mathrm{~V}$ \\
\hline Nominal output power & $1.5 \mathrm{~kW}$ \\
\hline
\end{tabular}

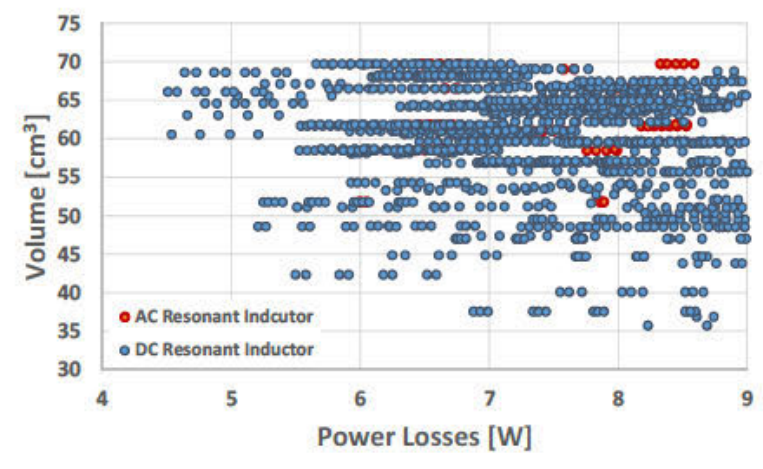

Fig. 6. Pareto front of the analyzed Resonant Switched Capacitor Converters

TABLE II: DESIGN DETAIIS OF THE IMPLEMENTED RESONANT SWITCHED CAPACITOR CONVERTER

\begin{tabular}{|l|c|}
\hline Component & Volume \\
\hline Bus capacitors Ceralink 20uF & $8.2 \mathrm{~cm}^{3}$ \\
\hline Resonant Capacitors MLCC X7R 5uF & $2 \mathrm{~cm}^{3}$ \\
\hline 55uH Resonant Inductance MPP 55071 & $28 \mathrm{~cm}^{3}$ \\
\hline Transistors 2 MOSFETS per switch & $7.2 \mathrm{~cm}^{3}$ \\
\hline Total & $45.4 \mathrm{~cm}^{3}$ \\
\hline
\end{tabular}

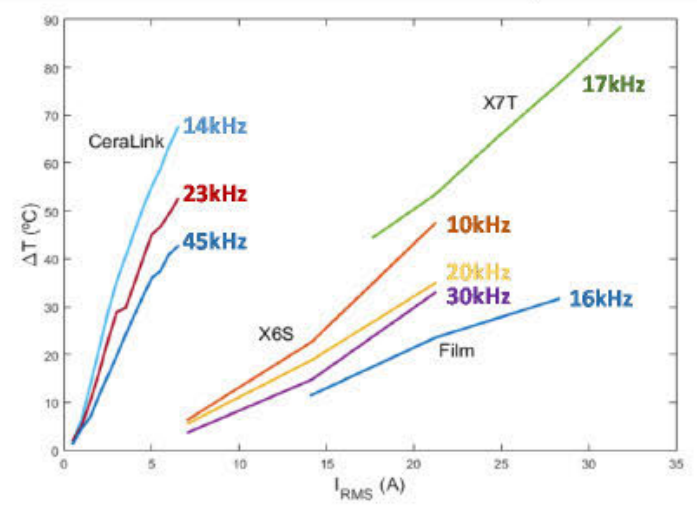

Fig 7 Temperature rise of the resonant capacitors in the case of different capacitor technologies

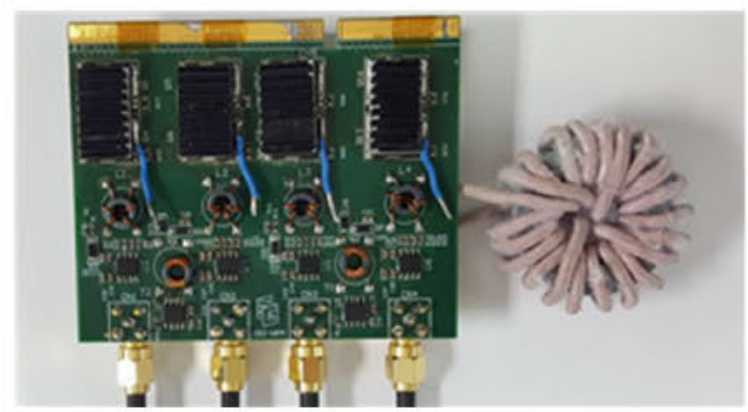

Fig 8 Implemented Resonant Switched Capacitor Converter

The implemented prototype is capable of processing $4.5 \mathrm{~kW}$, as demanded by the specifications, and its power density is higher than $65 \mathrm{~kW} / \mathrm{dm}^{3}$. The predicted power losses were around $6 \mathrm{~W}$ due to relatively high $\mathrm{I}_{\text {open }}$ current needed for the ZVS (between 4A and 6A). Figure 8 shows a photograph of the implemented converter. 


\section{EXPERIMENTAL RESULTS AND ANALYSIS OF THE INDUCTOR CURRENT}

Figures 9 and 10 show the most important waveforms of the analyzed converters, the resonant current and drain-source voltage of Q2 and Q4, at nominal conditions, $\mathrm{V}_{\text {out }}=700$ and $\mathrm{P}_{\text {out }}=1.5 \mathrm{~kW}$. In both cases the conducting MOSFET is turned off with, approximately, 5A. Once the transistor is turned off, the MOSFET's parasitic capacitances start to resonate with the resonant inductor and the drain-source voltages start to charge/discharge. This transition can be observed as a linear current change in a very short period of time in both figures. The conducting MOSFET has to be turned off with high levels of resonant current due to high $\mathrm{C}_{\text {oss }}$ of the employed CoolMOS and its highly nonlinear characteristic. Due to relatively high value of resonant current needed for this soft transition (4A$6 \mathrm{~A})$, the resonant current does not have the expected sinusoidal shape and the switching frequency can be significantly higher than the resonant frequency, especially at light load levels when the expected peak of resonant current is comparable with the resonant current just after transient. For example, the resonant frequency is $9.6 \mathrm{kHz}$, but the switching frequency in the case of the AC resonant inductor is three times higher, while in the case of the DC resonant inductor is equal to the resonant frequency, just as expected, as a direct consequence of the shape of the resonant current

At extremely low levels of the load (below $1.5 \mathrm{~kW}$ ), when the peak of resonant current is low, the resonant current can have, practically, trapezoidal shape, or even more, due to the high level of the turn off current it might be impossible to reach ZVS and, consequently, high switching losses would occur. In the case of the low power operating point of the analyzed RSCC $\left(1.5 \mathrm{~kW} @ \mathrm{~V}_{\text {out }}=700 \mathrm{~V}\right)$ the peak of the resonant current should be around $\pi \mathrm{P}_{\text {out }} / \mathrm{V}_{\text {out }} \approx 7 \mathrm{~A}$ which is very close to the current needed for the soft transition and it would lead to significantly high operating frequency producing significant losses in the magnetic core, conductors and transistors. In order to avoid these losses, a cycle skipping modulation should be applied in order to increase the peak of the resonant current as it will be presented later.

Comparing it with the case when the resonant inductor is in series with the resonant capacitor, the DC resonant inductor handles only one half of the excursion of the magnetic field, but at the double frequency. As the $\beta$ factor in the Steinmetz equation is, approximately, between 2 and 2.5 for the materials of interest, the core losses will be in the worst case equal in both resonant converters as the $\alpha$ factor should be higher than 2 to have higher cores losses in the case of the DC resonant inductor. Speaking about the losses in the conductors, DC resonant inductor has a major part of the current in the DC part of the spectrum and, therefore, the conduction losses will be smaller. However, the biggest advantage of the RSCC with DC resonant inductor is that it can correctly operate even without load. To keep the voltage of the bus capacitors balanced, RSCC has to operate even without load. When the DC resonant inductor is applied, it does not need any special modulation, like cycle skipping, to operate correctly fulfilling ZVS conditions and keeping the voltages balanced.

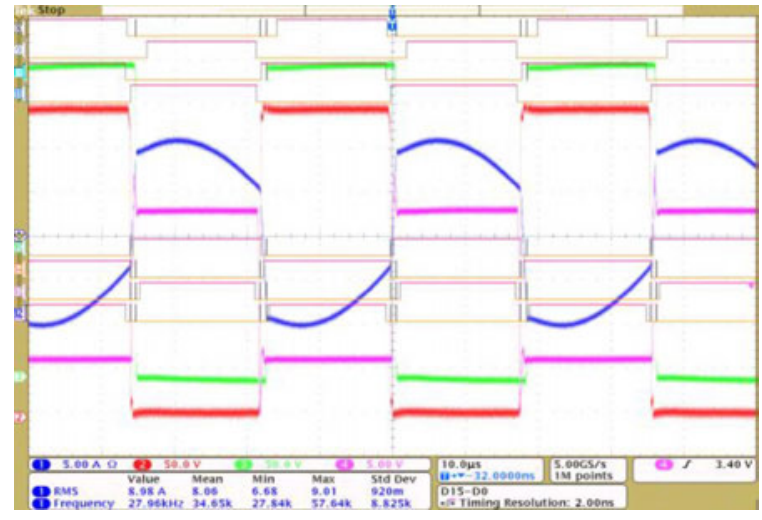

Fig 9 Resonant current and MOSFET drain-source voltages in the case of $\mathrm{AC}$ resonant inductor

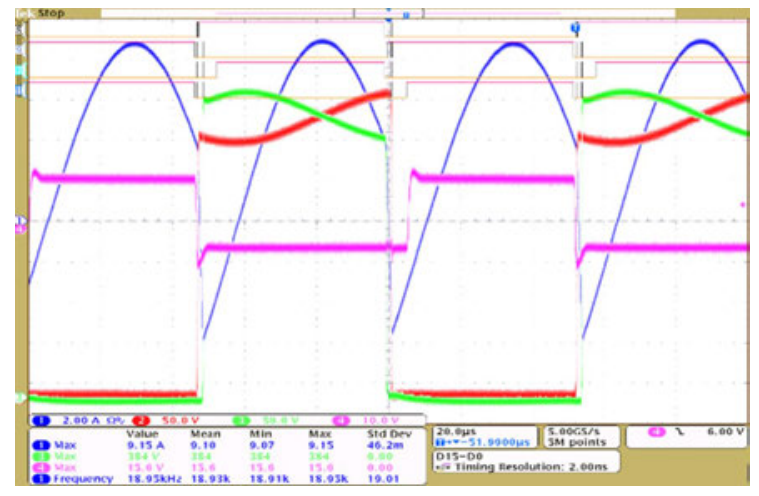

Fig 10 Resonant current and MOSFET drain-source voltages in the case of DC resonant inductor

In Figures 9 and 10 can be observed that drain source voltage of switches differ depending on the position of the resonant inductor. In one case the voltage is clamped to the input voltage and in the other case it is the output voltage minus the voltage in the resonant capacitor, which has some ripple.

\section{RSCC operating at light loads}

As it has been explained earlier, the peak of the resonant current decreases when the output power is decreased as shown in Figure 11. In the case of the AC resonant inductor this might be a problem because as the peak of the resonant current falls below the value that is necessary to achieve ZVS could lead to important power losses. Even more, in the case of the analyzed system, in the low power conditions this is what exactly happens and, in order to avoid it, it is necessary to employ cycle skipping. For example, if one resonant cycle is skipped, the peak of the resonant current is doubled and ZVS could be achieved. Figure 12 shows possible cycle skipping strategies and at the same time illustrates the bad side of this approach. In the first strategy, the resonance is started and it is let to naturally end after half the resonant cycle, the pause is made and then the second half of resonant cycle is performed. It can be seen that whenever the current reaches zero there are high frequency oscillations of drain-source voltage (pink trace) due to the resonance between the MOSFET $\mathrm{C}_{\text {oss }}$ and resonant inductor. This kind of oscillations can be observed in any converter that operates in Discontinuous Conduction Mode. 
These oscillations produce power losses which are not present if pulses are not skipped. Also, in order to start the resonance, hard discharge of the MOSFET's $C_{\text {oss }}$ occurs and soft turn on is impossible. To decrease the amount of power losses due to these two mechanisms, in the second approach a complete cycle is performed, with one ZVS transition, and then the needed pause is made, Fig. 13. With this strategy the power losses due to hard turn on and due to the parasitic oscillations are decreased to one half. For the analyzed RSCC converter at $1.5 \mathrm{~kW} @ \mathrm{~V}_{\text {out }}=700 \mathrm{~V}$ the power losses were $14 \mathrm{~W}$ for the first strategy and $12 \mathrm{~W}$ in the second case

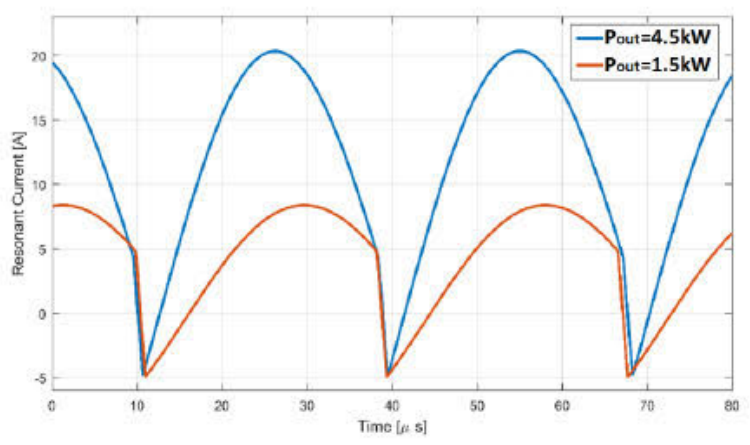

Fig 11 Comparison of RSCC resonant currents in the case of the nominal and full load - DC resonant inductor design

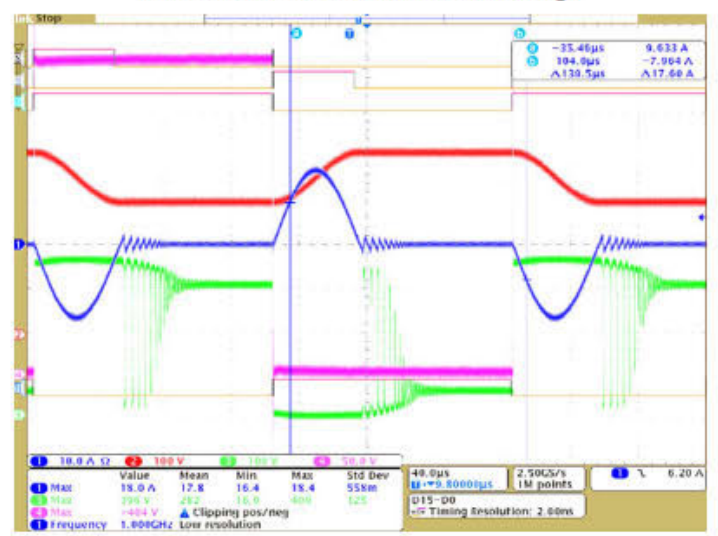

Fig 12 Half cycle resonance Resonant current (blue), resonant capacitor voltage (red) and MOSFET $V_{d s}$ (green and pink) in the case of resonant inductor at $\mathrm{AC}$ side and nominal output power

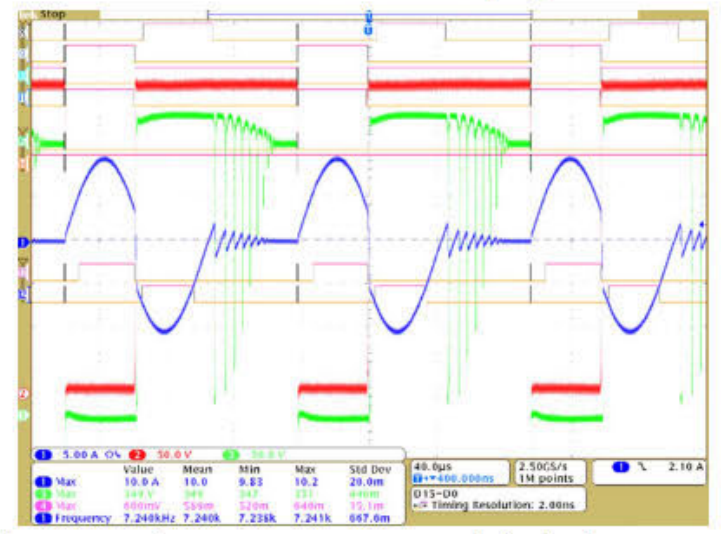

Fig 13 One cycle resonance Resonant current (yellow) and MOSFET $V_{d s}$ (blue and pink) in the case of resonant inductor at $\mathrm{AC}$ side and nominal output power
In the case of the RSCC with DC resonant inductor the ZVS condition is easier to accomplish as it is shown in Figure 11. In this figure resonant current at nominal and full load are compared. The negative current is needed for the ZVS and it helps increasing the peak of the resonant current (in order to maintain the needed DC level of the input current). Even when the RSCC is without load, the current will resonate and the MOSFET transitions are partially soft, Figure 14 . In the case when the output power from the RSCC is $0 \mathrm{~W}$, the measured power losses are less than 5W. At full load $(4.4 \mathrm{~kW} @$ Vout=700V) the measured power losses were $33.3 \mathrm{~W}$, Figure 15, while at nominal load $(1.5 \mathrm{~kW} @$ Vout=700V) the measured power losses are $8.25 \mathrm{~W}$ (50\% lower than in the case of $\mathrm{AC}$ resonant inductor with cycle skipping), Fig 16. The measured power loss is around $2 \mathrm{~W}$ higher than the calculated one and further work must be performed to analyze the difference between the theoretical and measured efficiency.

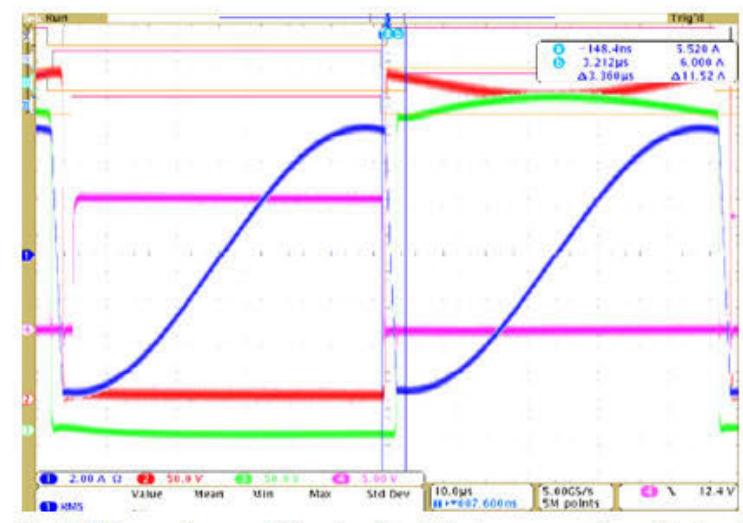

Fig 14 Resonant current (blue trace) and drain-source voltages (red and green traces) when RSCC operates without load - case of DC resonant inductor

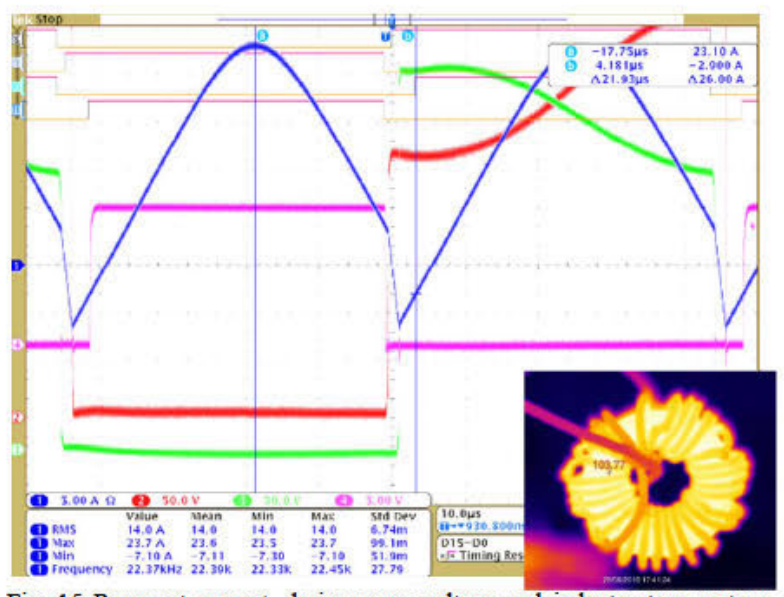

Fig 15 Resonant current, drain-source voltage and inductor temperature when the resonant converter operates in its worst case (output power of $44 \mathrm{~kW}$ ) 


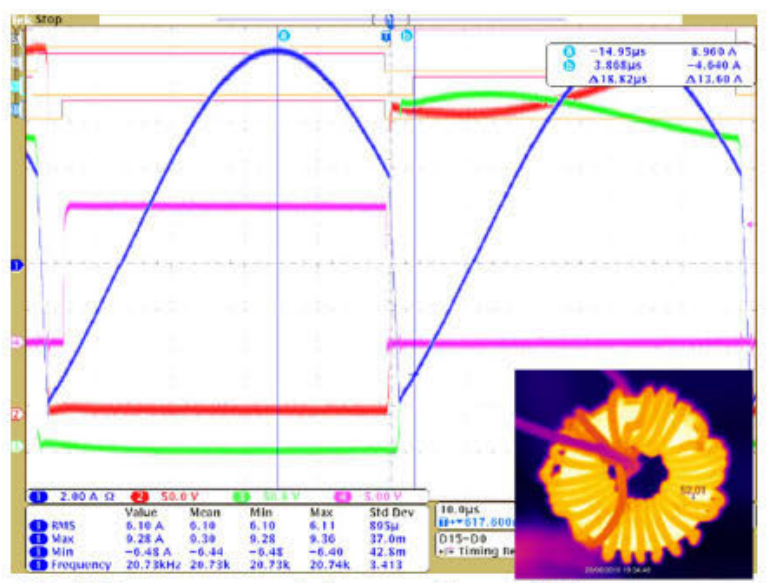

Fig 16 Resonant current, drain-source voltage and inductor temperature when the resonant converter processes its nominal power of $15 \mathrm{~kW}$

\section{CONCLUSIONS}

Multi-stage converters that include a Resonant Switched Capacitor Converter (RSCC) are normally employed in the solutions that require high efficiency and power density. The $\mathrm{RSCC}$ can be implemented with the resonant inductor in series with the resonant capacitor (AC inductor approach) or with the resonant inductor in series with the input source (DC inductor approach). The main difference between these two implementations is the shape and frequency of the resonant current. In the case of the $\mathrm{AC}$ resonant inductor, the shape and frequency of the current are load dependent. It is a sine wave, for heavy loads, while in the case of light loads, the current has, practically, trapezoidal waveform. In the case of the DC resonant inductor, the current is a rectified sine wave almost for all loads. This difference in the current waveforms is of the outmost importance and the RSCC with DC resonant inductor can achieve $50 \%$ less power losses and designs that occupy $40 \%$ less volume. Due to the load dependent resonant current the RSCC with AC resonant current cannot achieve ZVS even at nominal load and techniques such as cycle skipping has to be applied. Nevertheless, cycle skipping might produce additional power losses due to the parasitic oscillations between the resonant inductance and MOSFET's $\mathrm{C}_{\text {oss. }}$. On the other hand, RSCC with DC resonant inductor operates without any problem at light load ( $1.5 \mathrm{~kW}$ of output power) with only $8.25 \mathrm{~W}$ of power losses. The achieved power density of the designed RSCC is higher than $65 \mathrm{~kW} / \mathrm{dm}^{3}$.

\section{REFERENCES}

[1] M Chen, K K Afridi, S Chakraborty and D J Perreault, "Multitrack Power Conversion Architecture," in IEEE Transactions on Power Electronics, vol 32, no 1, pp 325-340, Jan 2017

[2] Y Lei; W C Liu; R C N Pilawa-Podgurski, "An Analytical Method to Evaluate and Design Hybrid Switched-Capacitor and Multilevel Converters," in IEEE Transactions on Power Electronics doi: 10 1109/TPEL 20172690324

[3] M Vasic, J A Oliver, P Alou, P: Grbovic and J A Cobos, "Experimental Evaluation of Capacitors for High Power Resonant Converters", in Proceedings of International Exhibition and Conference for Power Electronics, Intelligent Motion, Renewable Energy and Energy Management, PCIM Europe 2017

[4] I Oota, T Inoue, and F Ueno, "A realization of low-power supplies using switched-capacitor transformers and its analysis," Trans IECE Jpn, vol J66-C, no 8, pp 576-583, Aug 1983 (in Japanese)
[5] A Ioinovici, "Switched-capacitor power electronics circuits," IEEE Circuits Syst Mag, vol 1, no 3, pp 37-42, Sep 2001

[6] F Zhang, L Du, F Z Peng, and Z Qian, "A new design method for highpower high-efficiency switched-capacitor dc-dc converters," IEEE Trans Power Electron, vol 23, no 2, pp 832-840, Mar 2008

[7] $M$ Shen, F $Z$ Peng, and L M Tolbert, "Multilevel dc-dc power conversion system with multiple dc sources," IEEE Trans Power Electron, vol 23, no 1, pp 420-426, Jan 2008

[8] O Keiser, P K Steimer, and J W Kolar, "High power resonant switched capacitor step-down converter," in Proc IEEE PESC2008, Jun , pp 27722777

[9] D Cao and F Z Peng, "Zero-current-switching multilevel modular switched-capacitor DC-DC converter," in Proc IEEE ECCE2009, Sep, pp 3516-3522

[10] D Cao and F Z Peng, "A family of zero current switching switched capacitor DC-DC converters," in Proc IEEE APEC2010, Feb , pp 13651372

[11] Ming Xu, J Sun and F C Lee, "Voltage divider and its application in the two-stage power architecture," Twenty-First Annual IEEE Applied Power Electronics Conference and Exposition, 2006 APEC 06, Dallas, TX, 2006, pp 7 pp -

[12] Q Jin; M Vasic, "Optimized Design of GaN Switched-CapacitorConverter Based Envelope Tracker for Satellite Application," in IEEE Journal of Emerging and Selected Topics in Power Electronics, vol PP, no 99 ,

[13] P J Grbović, A Lidozzi, L Solero and F Crescimbini, "Performance evaluation for the five-level unidirectional T-rectifier in high-speed electric generating units", IEEE Trans Industry Applications, Early Access

[14] K Sano and H Fujita, "Performance of a High-Efficiency SwitchedCapacitor-Based Resonant Converter With Phase-Shift Control," in IEEE Transactions on Power Electronics, vol 26, no 2, pp 344-354, Feb 2011

[15] P J Grbovic, P Delarue and P Le Moigne, "A Novel Three-Phase Diode Boost Rectifier Using Hybrid Half-DC-Bus-Voltage Rated Boost Converter," in IEEE Transactions on Industrial Electronics, vol 58, no 4, pp 1316-1329, April 2011

[16] M Kasper, R M Burkart, G Deboy and J W Kolar, "ZVS of Power MOSFETs Revisited," in IEEE Transactions on Power Electronics, vol 31 , no 12 , pp 8063-8067, Dec 2016 